\title{
VALIDATION OF A STREAM AND RIPARIAN HABITAT ASSESSMENT PROTOCOL USING STREAM SALAMANDERS IN THE SOUTHWEST VIRGINIA COALFIELDS ${ }^{1}$
}

\begin{abstract}
Sara E. Sweeten ${ }^{2}$ and W. Mark Ford
Abstract: Within the central Appalachia Coalfields, the aquatic impacts of largescale land uses, such as surface mining, are of particular ecological concern. Identification and quantification of land use impacts to aquatic ecosystems are a necessary first step to aid in mitigation of negative consequences to biota. However, quantifying physical environmental quality such as stream and riparian habitat often can be quite difficult, particularly when there is time or fiscal limitations. As such, standard protocols such as the U.S. EPA's Stream Habitat Rapid Bioassessment Protocol have been established to be cost- and time-effective. This protocol estimates ten different stream and riparian conditions on a scale of 0 to 20 . Unfortunately, using estimations can be problematic because of large potential variation in the scoring depending on differences in training, experience, and opinion of the personnel doing the estimations. In order to help negate these biases and provide a simplified process, the U.S. Army Corps of Engineers (USACE) developed a functional assessment for streams that measures 11 stream and riparian variables along with watershed land use to calculate three different scores, a hydrology score, biogeochemical score, and habitat score. In our study, we examined the correlation of stream salamander presence and abundance to the three USACE scores. In the summer of 2013, we visited 70 sites in the southwest Virginia Coalfields multiple times to collect salamanders and quantify stream and riparian microhabitat parameters. Using occupancy and abundance analyses, we found strong relationships among three Desmognathus spp. and the USACE Habitat FCI score. Accordingly, the Habitat FCI score provides a reasonable assessment of physical instream and riparian conditions that may serve as a surrogate for understanding the community composition and integrity of aquatic salamander in the region.
\end{abstract}

Additional Key Words: Central Appalachia; headwater streams; rapid assessment; coal mining

${ }^{1}$ Oral paper presented at the 2015 National Meeting of the American Society of Mining and Reclamation, Lexington, KY Reclamation Opportunities for a Sustainable Future June 6-11, 2015.

2 Sara Sweeten, Post-doctoral Research Associate, Department of Fisheries and Wildlife Conservation, Virginia Polytechnic Institute and State University, Blacksburg, VA 24061. W. Mark Ford, Unit Leader, U.S. Geological Survey, Virginia Cooperative Fish and Wildlife Research Unit, Department of Fisheries and Wildlife Conservation, Virginia Polytechnic Institute and State University, Blacksburg, VA, 24061.

Journal American Society of Mining and Reclamation, 2016 Volume 5, Issue 1 pp 45 - 66 DOI: http://doi.org/10.21000/JASMR16010045 


\section{Introduction}

Much is still unknown about many of the terrestrial and aquatic ecosystem dynamics and interactions that are changed by dramatic landscape alterations from coal mining practices (Stout and Wallace, 2005; Simmons et al., 2008). High quality physical stream and riparian habitat provides critical areas for aquatic organisms to feed, reproduce, and take refuge from both predators as well as high flow events (Hynes, 1968; Maddock, 1999). Without good instream and riparian habitat, mitigation of water chemistry parameters alone will not facilitate subsequent aquatic biota recovery. However, accurately assessing and measuring physical stream and riparian habitat can be difficult because of fiscal and personnel constraints. Consequently regulators and mangers are accordingly challenged by the inability to understand current conditions, restoration needs, and proper management priorities and directions.

In Virginia, the Virginia Department of Environmental Quality (VADEQ) is responsible for ensuring the compliance of mining operations under the Clean Water Act (CWA) and the Surface Mining Control and Reclamation Act (SMCRA). In order to determine stream health, the VADEQ requires coal companies to monitor water chemistry parameters as well as benthic macroinvertebrates using the Virginia Stream Condition Index (VA-SCI), a multi-metric benthic macroinvertebrate assessment protocol (Burton and Gerritsen, 2003). Additionally, the EPA Rapid Bioassessment Protocol (RBP) habitat assessment is used to visibly estimate instream habitats as well as some limited riparian habitat characteristics such as bank stability and bank vegetation cover (Barbour et al., 1999). Although this habitat assessment method is time and financially effective, overall it is a qualitative estimation that could be biased because of inexperienced or improperly trained personnel. A more quantitative method that takes into account surrounding riparian quality may provide more accurate, reliable results.

In 2010 the U.S. Army Corps of Engineers developed the Operational Draft Regional Guidebook for the Functional Assessment of High-gradient Ephemeral and Intermittent Headwater Streams in Western West Virginia and Eastern Kentucky using the Hydrogeomorphic approach (HGM) in order to provide a cost and time effective stream and riparian habitat assessment that is quantitative (Noble et al., 2010). The HGM protocol calculates three Functional Capacity Index (FCI) scores: Hydrology, Habitat, and Biogeochemical. Hydrological function is defined as "the ability of the high-gradient headwater stream to dissipate energy associated with 
flow velocity and transport water downstream" (Noble et al., 2010). The Hydrological FCI incorporates substrate embeddedness, substrate size, large woody debris (LWD), stream bank erosion, and watershed land use. Habitat function is defined as "the capacity of the high-gradient headwater stream ecosystem to provide critical life requisites to selected components of the vertebrate and invertebrate wildlife community" (Noble et al., 2010). The Habitat FCI uses the following variables: canopy cover, substrate embeddedness, substrate size, LWD, riparian tree diameter, tree snag density, sapling and shrub density, riparian tree species richness, detritus cover, herbaceous cover, and watershed land use. Biogeochemical function is defined as "the ability of high-gradient headwater stream ecosystem to retain and transfer inorganic materials needed for biological processes into organic forms and to oxidize those organic molecules back into elemental forms through respiration and decomposition" (Noble et al., 2010). Substrate embeddedness, LWD, riparian tree diameter, sapling and shrub density, detritus cover, herbaceous cover, and watershed land use are the variables that comprise the Biogeochemical FCI. Final scores for all three FCI components range from $0-1.0$ where a score of 1.0 indicates the function to be equal to that of a reference site.

Whereas the FCI habitat assessment approach was designed for a region immediately adjacent to the Virginia coalfields, the protocol does not contain variables specific only to the western West Virginia and eastern Kentucky region. The region defined by the FCI protocol is perhaps more similar than dissimilar to the Virginia coalfields physically and biologically, i.e., eastern Kentucky is in the same ecoregion as the Virginia coalfields (Ecoregion 69). Stream salamanders such as Desmognathus spp. are thought to be good indicators of riparian and instream habitat quality (Welsh and Ollivier, 1998; Welsh et al., 2005). A small validation study $(\mathrm{N}=10)$ of this approach showed positive correlations between stream salamander abundance and the Habitat FCI score (Noble et al., 2014). Additionally, our previous occupancy and abundance analyses of stream salamanders had strong relationships with riparian and instream habitat variables that are covariates that are also used in the FCI scores including canopy cover, stream substrate embeddedness, and stream bank erosion (Sweeten, 2015). We therefore decided to conduct two post hoc analyses (one using occupancy, one using abundance) to determine if there were any relationships among the three FCI scores and stream salamander metrics. 


\section{Methods}

\section{$\underline{\text { Regional Description }}$}

Our study area was located in Wise, Russell, and Dickenson counties in the southwest Virginia coalfields. This area is part of the Cumberland Plateau (Region 69d), a sub-region of the Central Appalachian Mountains (Omernik, 1987). Topography is characterized by steep mountains with narrow valleys with an average peak elevation of $760 \mathrm{~m}$ (Woodward and Hoffman, 1991). Most soils in this region are Utisols, Alfisols, and Inceptisols (McNab and Avers, 1995). Average annual precipitation is about $1150 \mathrm{~mm}$ with an average temperature of $13^{\circ} \mathrm{C}$ (Woodward and Hoffman, 1991; McNab and Avers, 1995). Regionally, it is estimated that $93 \%$ of the Cumberland Plateau is forested, $4 \%$ of the region is agricultural/open area, $2 \%$ is barren, and $1 \%$ is developed. Much of the open or barren classification is a result of past or current surface mining (VDGIF, 2005). The forested areas are characterized by a diverse mix of hardwood and conifers (Woodward and Hoffman, 1991). Common tree species include red oak (Quercus rubra), white oak (Quercus alba), pignut hickory (Carya glabra), red maple (Acer rubrum), yellow poplar (Liriodendron tulipifera), American beech (Fagus grandifolia), basswood (Tilia americana), and white pine (Pinus strobus) (McNab and Avers, 1995). Because of the steep topography, this region tends to have a high density of small- to medium-sized streams (McNab and Avers, 1995). Streams in this region are characterized by boulder/cobble substrate, moderate to high gradient, and low conductivity. The Cumberland Plateau has high levels of aquatic biodiversity and species richness, with many endemic species (Morse et al., 1993).

\section{$\underline{\text { Site Selection }}$}

We selected five 12 digit Hydrologic Unit Codes (HUC-12) watersheds in southwest Virginia as study sites (Table 1). These five watersheds are similar in area, located within the Cumberland Plateau and Mountains Region, and have active coal mining along with other land uses. We divided streams within these watersheds into segments by their stream order, and gave each stream segment in each watershed a unique identification number. We selected 70 first- or second-order stream segments using best professional judgment for sites that had both allowed landowner access and that we considered safe to sample. Because of a lack of accessible sites, we sampled 10 sites in the Pigeon Creek watershed and 10 sites in the Dumps Creek watershed. Roaring Fork and Rocky Fork watersheds each had 15 salamander sampling locations, and 20 sites were sampled in the Callahan Creek watershed. 
To accurately estimate detection rates, we visited 67 of the 70 locations three times each in 2013 (Bailey et al., 2004; MacKenzie and Royle, 2005). Because of access issues, we were only able to sample three of the sites twice in 2013. At each sampling location a $25 \mathrm{~m}$ long by $5 \mathrm{~m}$ wide quadrat was placed parallel to the stream channel with the stream center as the right or left edge of the quadrat (Hairston, 1986; Jung et al., 2000). Right or left quadrat placement was determined randomly using a coin flip. We hand-captured adult salamanders (all by overturning all rocks, detritus, and $\operatorname{logs}$ within the $25 \mathrm{~m}$ x $5 \mathrm{~m}$ quadrat at each sampling site). We identified all adult salamanders to species in the field and immediately released them to within $2 \mathrm{~m}$ of each capture location. All transformed salamanders (sexually mature and immature) were considered to be adults. A D-frame dip net was used to sample in-stream habitat (Davic, 1983; Gore, 1983). All larval salamanders were removed by hand from the dip net, placed in a bucket of fresh stream water for identification, and then released within $2 \mathrm{~m}$ of the capture location. Because of the difficulty of identifying larval salamanders to the species level, we identified larval salamanders to genus. Salamander surveys were approved by Virginia Tech Institutional Animal Use and Care Committee protocol 13-053-FIW.

Table 1. Information for the five HUC-12 study watersheds used in 2013 including watershed name, HUC-12 identification number, Virginia County(s) where the watershed is located and the area (square kilometers) of the watershed.

\begin{tabular}{lccc}
\hline Watershed name & HUC-12 & County & Watershed area (sq. km) \\
\hline Callahan Creek & 60102060103 & Wise & 54.7 \\
Dumps Creek & 60102050402 & Dickenson; Russell & 82.3 \\
Pigeon Creek & 60102060104 & Wise & 58.9 \\
Roaring Fork & 60102060101 & Wise & 66 \\
Rocky Fork & 60102050501 & Wise & 91 \\
\hline
\end{tabular}

\section{$\underline{\text { FCI Assessment Protocol }}$}

A full description of the original field protocols for the FCI protocol was defined by Noble et al. (2010). Although we largely followed the FCI protocol, some modifications were used in this study. First, because of site conditions habitat measurements were recorded from a $25 \mathrm{~m}$ x $10 \mathrm{~m}$ quadrat centered on the salamander quadrat rather than the $30.5 \mathrm{~m}$ x $15.2 \mathrm{~m}$ quadrat as suggested by the FCI protocol. Secondly, we took three canopy cover measurements, six detritus 
measurements, and six herbaceous cover measurements, rather than the 10 canopy cover, eight detritus, and eight herbaceous measurements recommended by the FCI protocol.

The Functional Capacity Index (FCI) protocol calculates three scores: Hydrology, Habitat, and Biogeochemical. Hydrological function is defined as "the ability of the high-gradient headwater stream to dissipate energy associated with flow velocity and transport water downstream" (Noble et al., 2010). The equation used for calculating the Hydrology FCI is:

$$
F C I=\left\{\frac{V_{W L U S E}+\frac{\left[V_{L W D}+\min \left(V_{S U B S T R A T E}, V_{E M B E D}, V_{B E R O}\right)\right]}{2}}{2}\right\}
$$

where $\mathrm{V}_{\mathrm{LWD}}=$ the number of down woody stems per $25 \mathrm{~m}$ of stream reach; $\mathrm{V}_{\text {SUBSTRATE }}=$ the median stream substrate particle size $(n=30) ; V_{\text {EMBED }}=$ the mean embeddedness of the stream channel $(\mathrm{n}=30) ; \mathrm{V}_{\text {BERO }}=$ the total percent of eroded stream channel bank, and $\mathrm{V}_{\text {WLUSE }}$ was calculated using land cover data from Maxwell et al. (2014), in ArcMap (ESRI, Redlands, California; www.esri.com).

Habitat function is defined as "the capacity of the high-gradient headwater stream ecosystem to provide critical life requisites to selected components of the vertebrate and invertebrate wildlife community" (Noble et al., 2010). One of two equations is used to calculate the Habitat FCI score. If there was an average channel canopy cover of $\geq 20$ percent, then the equation is:

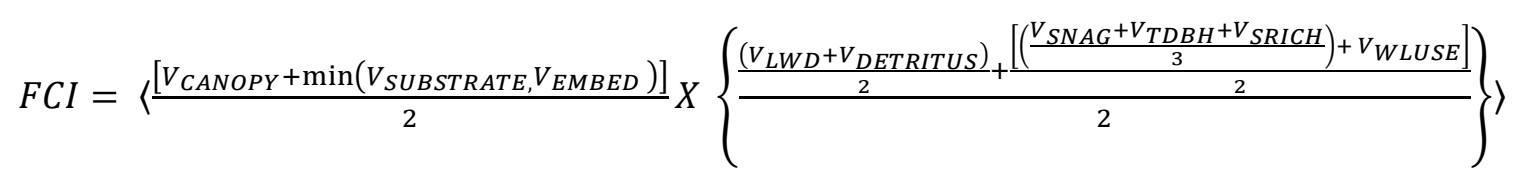

where $\mathrm{V}_{\text {CANOPY }}=$ mean percent canopy $\operatorname{cover}(\mathrm{n}=3)$; $\mathrm{V}_{\text {SUBSTRATE }}=$ the median stream substrate particle size $(n=30) ; V_{\text {EMBED }}=$ the mean embeddedness of the stream channel $(n=30) ; V_{L W D}=$ the number of down woody stems per $25 \mathrm{~m}$ of stream reach, $\mathrm{V}_{\text {DETRITUS }}=$ the mean percent detritus cover $(n=6) ; V_{\text {SNAG }}=$ the number of standing, dead snags per $25 \mathrm{~m}$ of stream, $V_{\mathrm{TDBH}}=$ the mean diameter at breast height $(\mathrm{DBH})$ of trees with $\mathrm{DBH} \geq 10 \mathrm{~cm} ; \mathrm{V}_{\text {SRICH }}=$ riparian vegetation species richness score per $25 \mathrm{~m}$ of stream reach; and VWLUSE was calculated using land cover data from Maxwell et al. (2014), in ArcMap.

If there was $\leq 20$ percent canopy cover, then the Habitat FCI was calculated using this equation: 
JASMR, 2016 Volume 5 Issue 1

$$
F C I=\left\langle\min \left(V_{E M B E D}, V_{\text {SUBSTRATE }}\right) X \frac{\left\{\left(\frac{V_{L W D}+V_{\text {DETRITUS }}}{2}\right)+\left[\frac{\left(\frac{V_{S N A G}+V_{S S D}+V_{H E R B}+V_{S R I C H}}{6}\right)+V_{W L U S E}}{4}\right]\right\}}{2}\right\rangle
$$

where $V_{\text {EMBED }}=$ the mean embeddedness of the stream channel $(n=30) ; V_{\text {SUBSTRATE }}=$ the median stream substrate particle size $(n=30) ; V_{L W D}=$ the number of down woody stems per $25 \mathrm{~m}$ of stream, $V_{\text {DETRITUS }}=$ the mean percent detritus cover $(n=6) ; V_{\text {SNAG }}=$ the number of standing, dead snags per $25 \mathrm{~m}$ of stream; $\mathrm{V}_{\mathrm{SSD}}=$ the number of saplings and shrubs per $25 \mathrm{~m}$ of stream reach, $\mathrm{V}_{\text {HERB }}=$ the mean percent cover of herbaceous vegetation $(\mathrm{n}=6) ; \mathrm{V}_{\text {SRICH }}=$ riparian vegetation species richness score per $25 \mathrm{~m}$ of stream reach; and $\mathrm{V}_{\text {WLUSE }}$ was calculated using land cover data from Maxwell et al. (2014), in ArcMap.

Biogeochemical function is defined as "the ability of a high-gradient headwater stream ecosystem to retain and transfer inorganic materials needed for biological processes into organic forms and to oxidize those organic molecules back into elemental forms through respiration and decomposition" (Noble et al., 2010). One of two equations was used to calculate the Biogeochemical FCI score. If there was a mean channel canopy cover of $\geq 20$ percent, then the equation is:

$$
F C I=\left\{V_{E M B E D} X \sqrt{\left[\frac{\left(\frac{V_{L W D}+V_{D E T R I T U S}+V_{T B D H}}{3}\right)+V_{W L U S E}}{2}\right]}\right\}
$$

where $\mathrm{V}_{\text {EMBED }}=$ the mean embeddedness of the stream channel $(n=30) ; V_{\text {LWD }}=$ the number of down woody stems per $25 \mathrm{~m}$ of stream; $\mathrm{V}_{\text {DETRITUS }}=$ the mean percent detritus cover $(\mathrm{n}=6) ; \mathrm{V}_{\text {TDBH }}$ $=$ the mean diameter at breast height $(\mathrm{DBH})$ of trees with $\mathrm{DBH} \geq 10 \mathrm{~cm}$; and $\mathrm{V}_{\text {WLUSE }}$ was calculated using land cover data from Maxwell et al. (2014), in ArcMap.

If the mean channel canopy cover was $\leq 20$ percent, then the equation is:

$$
F C I=\left\{V_{E M B E D} X \sqrt{\left[\frac{\left(\frac{\left.V_{L W D}+V_{D E T R I T U S}+V_{S S D}+V_{H E R B}\right)+V_{W L U S E}}{4}\right]}{4}\right]}\right\}
$$

where $\mathrm{V}_{\mathrm{EMBED}}=$ the mean embeddedness of the stream channel $(\mathrm{n}=30) ; \mathrm{V}_{\mathrm{LWD}}=$ the number of down woody stems per $25 \mathrm{~m}$ of stream; $\mathrm{V}_{\text {DETRITUS }}=$ the mean percent detritus cover $(\mathrm{n}=6) ; \mathrm{V}_{\mathrm{SSD}}=$ the number of saplings and shrubs per $25 \mathrm{~m}$ of stream reach; $\mathrm{V}_{\mathrm{HERB}}=$ the mean percent cover of 
herbaceous vegetation $(n=6)$; and $V_{\text {WLUSE }}$ was calculated using land cover data from Maxwell et al. (2014), in ArcMap.

\section{Occupancy and Abundance Modeling}

To assess salamander occupancy and detection probabilities and abundance estimates, we used the Program PRESENCE software (USGS, Laurel, MD; www.mbr-pwrc.usgs.gov/software). Program PRESENCE was developed to examine and rank multiple hypotheses using an information-theoretic approach (AIC) and maximum likelihood to determine the best-fit model for the data (Bailey et al., 2007; Kroll et al., 2010). Within Program PRESENCE, we used "SingleSeason" models to examine occupancy and the "Royle Repeated Count" models (also known as $\mathrm{N}$-mixture models) to estimate salamander abundances from repeated site visits (Royle, 2004).

Additionally, we estimated detection probabilities for each species to determine which environmental conditions most influenced detection. Detection is important in AIC analyses in order to produce the most reliable estimates of occupancy or abundance. Without considering detection in data analysis, a species true presence may be misclassified as absent when the species was present but not detected. Often, this will then underestimate the occupancy probability and abundance estimate (Dorazio et al., 2006; MacKenzie, 2006). We used a two-step method to determine which detection covariates to include for each species group in the occupancy analysis (Burnham and Anderson, 2002). We ran seven a priori detection covariates for each species group against the null (intercept) model. The detection covariates included stream flow above base flow, stream flow below base flow, water temperature, air temperature, soil temperature, current weather, and weather in the past 24 hours. Prior to analysis, we normalized continuous detection covariates as well as FCI scores in order to compare beta (effect size) values among models.

\section{$\underline{\text { Results }}$}

We captured 1,145 stream salamanders consisting of nine species during the 207 surveys over the 2013 collection. Because of the large number of Eurycea spp. larval salamanders and the small number of adult Eurycea, we combined larval and adult Eurycea longicauda (Long-tailed Salamander) and Eurycea cirrigera (Southern Two-lined Salamander) to the genus-level for the Eurycea spp. group. Based on results from Sweeten (2015), the four salamander groups that had sufficient data for occupancy analysis were also used for analysis of abundance: Desmognathus 
fuscus (Northern Dusky Salamander), Desmognathus monticola (Seal Salamander), Desmognathus ochrophaeus (Mountain Dusky Salamander), and Eurycea spp.

\section{Occupancy}

The Habitat FCI Model was the best occupancy model for Desmognathus fuscus with an AIC weight of 0.85 and strong empirical support with a $\triangle \mathrm{ACI}$ of 0.00 (Table 2). The beta estimate for the Habitat FCI score was $9.4(\mathrm{SE}=2.90)$ and showed a strong positive correlation to D. fuscus presence (Table 3). Individual site occupancy probabilities for $D$. fuscus ranged from 0.01 to 0.89 (Fig. 1A). The Hydrology FCI Model also had moderate empirical support with a $\Delta$ AIC of 3.58 and an AIC weight of 0.14 (Table 2; Fig. 1C). A model is considered to have strong empirical support if it has a $\Delta$ AIC $<2.0$. Whereas a model with a $\triangle$ AIC of 2.0-4.0 is considered to have moderate empirical support.

The only occupancy model with empirical support for Desmognathus monticola was the Biogeochemical FCI Model with an AIC weight of 0.97 (Table 2). D. monticola showed a strong positive correlation to the Biogeochemical FCI score with a beta estimate of 10.89 ( $\mathrm{SE}=2.95$; Table 2). Individual site occupancy probabilities ranged from 0.04 to 0.94 (Fig. 1B).

The best occupancy model for Desmognathus ochrophaeus was the Habitat FCI Model which had an AIC weight of 0.63 (Table 2). Occupancy of D. ochrophaeus was positively correlated to the Habitat FCI scores (Beta estimate $=4.43 ; \mathrm{SE}=1.40$; Table 3), and individual site occupancy estimates ranged from 0.14 to 0.82 (Fig. 1A). There was also empirical support for the Biogeochemical FCI Model with a $\Delta$ AIC of 1.11 and an AIC weight of 0.36 (Table 2; Fig. 1B).

The best occupancy model for Eurycea spp. was the Hydrology FCI Model with an AIC weight of 0.47 (Table 2). The beta estimate of 2.90 ( $\mathrm{SE}=1.77$ ) shows a positive correlation between Eurycea spp. occupancy and Hydrology FCI scores (Table 3). Individual site occupancy estimations ranged from 0.50 to 0.87 (Fig. 1C). The Biogeochemical FCI Model also had substantial empirical support for Eurycea spp. with a $\triangle$ AIC of 0.91 (Table 2). However, the beta estimate for the Biogeochemical FCI score was low at 0.45 with a large standard error of 1.43. Individual site estimates of occupancy for Eurycea spp. ranged from 0.70 to 0.76 (Fig. 1B). 
JASMR, 2016 Volume 5 Issue 1
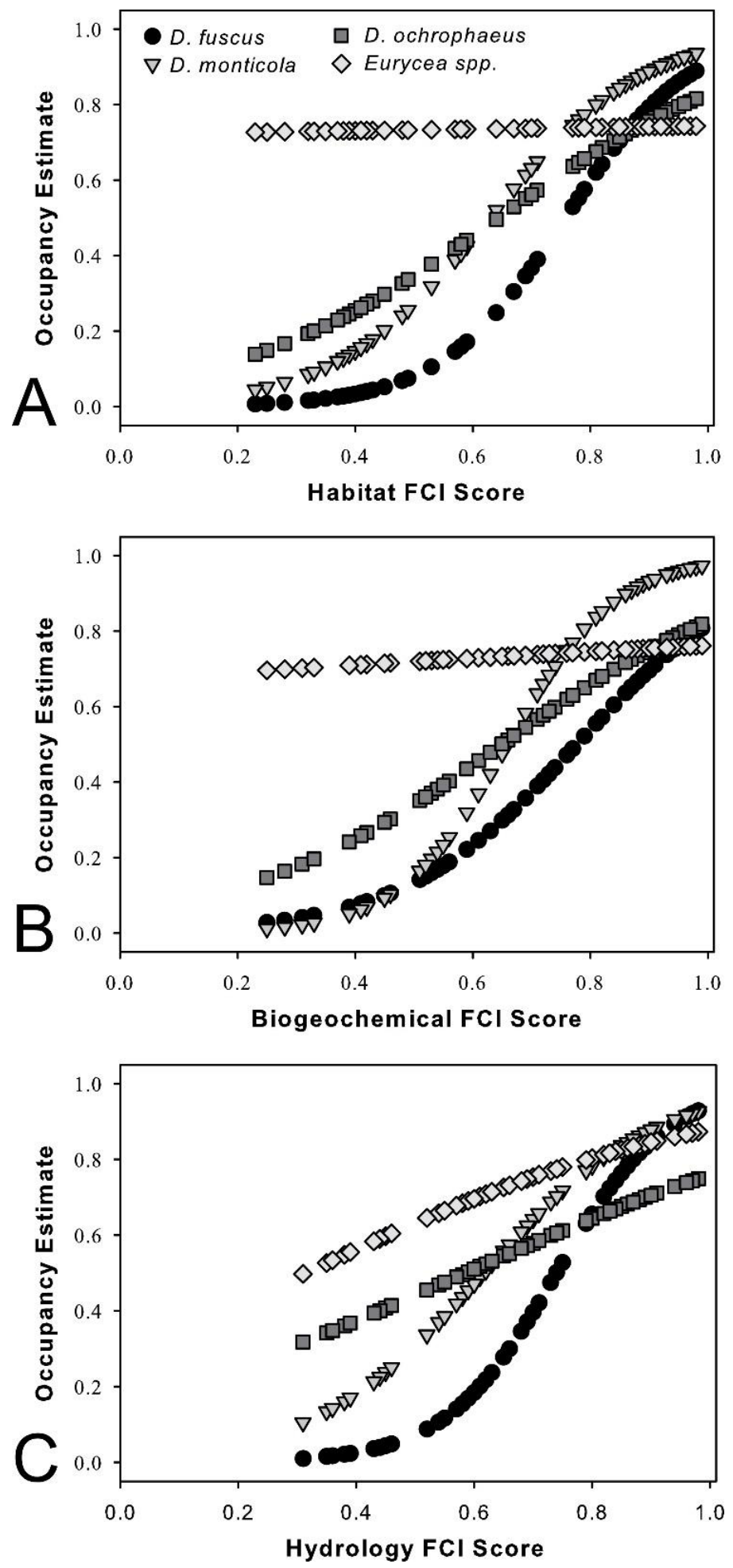

Figure 1. Individual site estimations of occupancy $(\Psi)$ and the Habitat Functional Capacity Index (FCI; see Noble et al. 2010) scores (A), the Biogeochemical FCI scores (B), and the Hydrology FCI scores (C) for Desmognathus fuscus (circles), Desmognathus monticola (triangles), Desmognathus ochrophaeus (squares), and Eurycea spp. (diamonds), southwest Virginia, summer 2013. 
Additionally, there was moderate empirical support for the Habitat FCI Model which had a $\triangle$ AIC of 2.91 and an AIC weight of 0.11 (Table 2). The beta estimate for the Habitat FCI score was small at $0.11(\mathrm{SE}=1.30)$, and individual site occupancy estimations ranged from 0.73 to 0.74 (Table 3; Fig. 1A).

Table 2. Model results for occupancy probabilities of FCI scores including the number of parameters in each model (K), Akaike's Information Criterion (AIC) rankings, $\Delta$ AIC, and AIC weight $\left(\omega_{i}\right)$ for the four stream salamander groups, southwest Virginia, 2013.

\begin{tabular}{|c|c|c|c|c|}
\hline FCI Occupancy Models & $\mathrm{K}$ & AIC & $\Delta \mathrm{AIC}^{1}$ & $\omega_{\mathrm{i}}$ \\
\hline \multicolumn{5}{|l|}{ Desmognathus fuscus } \\
\hline$\Psi($ HabitatFCI $), \mathrm{p}(\text { Rain } 24)^{2}$ & 4 & 173.53 & 0.00 & 0.8516 \\
\hline$\Psi($ HydrologyFCI), p(Rain24) & 4 & 177.11 & 3.58 & 0.1422 \\
\hline$\Psi($ BiogeochemicalFCI), p(Rain24) & 4 & 183.38 & 9.85 & 0.0062 \\
\hline$\Psi($ Null $), \mathrm{p}($ Rain24) & 3 & 198.22 & 24.69 & 0.0000 \\
\hline \multicolumn{5}{|l|}{ Desmognathus monticola } \\
\hline$\Psi($ BiogeochemicalFCI $), \mathrm{p}(\text { SoilT })^{3}$ & 4 & 210.86 & 0.00 & 0.9707 \\
\hline$\Psi($ HabitatFCI $), p($ SoilT $)$ & 4 & 217.87 & 7.01 & 0.0292 \\
\hline$\Psi($ HydrologyFCI), p(SoilT) & 4 & 228.97 & 18.11 & 0.0001 \\
\hline$\Psi($ Null $)$, p(SoilT) & 3 & 242.39 & 31.53 & 0.0000 \\
\hline \multicolumn{5}{|l|}{ Desmognathus ochrophaeus } \\
\hline$\Psi($ HabitatFCI), p(SoilT*Rain) & 5 & 210.25 & 0.00 & 0.6263 \\
\hline$\Psi($ BiogeochemcialFCI $), \mathrm{p}\left(\text { SoilT }^{*} \text { Rain }\right)^{4}$ & 5 & 211.36 & 1.11 & 0.3595 \\
\hline$\Psi($ HydrologyFCI), p(SoilT*Rain) & 5 & 218.61 & 8.36 & 0.0096 \\
\hline$\Psi($ Null $)$, p(SoilT*Rain) & 4 & 220.09 & 9.84 & 0.0046 \\
\hline \multicolumn{5}{|l|}{ Eurycea spp. } \\
\hline$\Psi($ HydrologyFCI), p(SoilT*Rain) & 5 & 260.06 & 0.00 & 0.4732 \\
\hline$\Psi($ Null), p(SoilT*Rain) & 4 & 260.97 & 0.91 & 0.3002 \\
\hline$\Psi($ BiogeochemicalFCI $), \mathrm{p}($ SoilT*Rain $)$ & 5 & 262.87 & 2.81 & 0.1161 \\
\hline$\Psi($ HabitatFCI $), \mathrm{p}($ SoilT*Rain $)$ & 5 & 262.97 & 2.91 & 0.1104 \\
\hline \multicolumn{5}{|c|}{$\begin{array}{l}\text { Models with a } \triangle \mathrm{AIC}<2 \text { are considered to have a substantial level of empirical support while models with a } \Delta \mathrm{AIC} \\
\text { of } 2-4 \text { are considered to have a moderate level of empirical support. }\end{array}$} \\
\hline \multicolumn{5}{|c|}{${ }^{2}$ Rain 24 is a binomial of rain in the past 24 hours } \\
\hline \multicolumn{5}{|l|}{${ }^{3}$ SoilT is Soil Temperature } \\
\hline${ }^{4}$ Rain is a binomial for current weatl & & & & \\
\hline
\end{tabular}


Table 3. Beta estimates and standard errors for each covariate in the top occupancy models $(\triangle \mathrm{AIC}<4)$ for four salamander groups, southwest Virginia, 2013.

\begin{tabular}{|c|c|c|}
\hline Top Occupancy FCI Models & Beta & Standard Error \\
\hline \multicolumn{3}{|l|}{ Desmognathus fuscus } \\
\hline 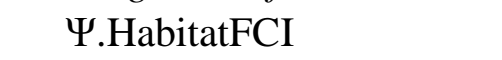 & 9.4156 & 2.8996 \\
\hline 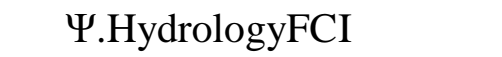 & 10.6577 & 3.3821 \\
\hline \multicolumn{3}{|l|}{ Desmognathus monticola } \\
\hline 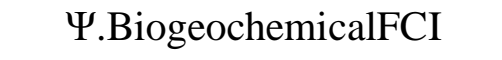 & 10.8927 & 2.9531 \\
\hline \multicolumn{3}{|l|}{ Desmognathus ochrophaeus } \\
\hline 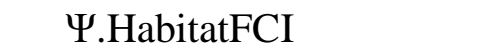 & 4.4261 & 1.3975 \\
\hline 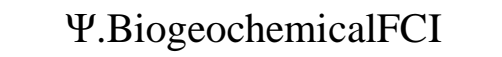 & 4.4126 & 1.4660 \\
\hline \multicolumn{3}{|l|}{ Eurycea spp. } \\
\hline$\Psi$. HydrologyFCI & 2.8970 & 1.7669 \\
\hline 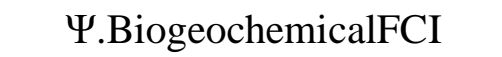 & 0.4496 & 1.4295 \\
\hline 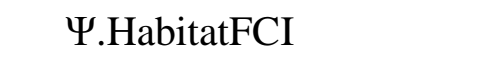 & 0.1112 & 1.2998 \\
\hline
\end{tabular}

\section{$\underline{\text { Abundance }}$}

The best abundance model for Desmognathus fuscus was the Habitat FCI Model with an AIC weight of 0.60 (Table 4), and a beta estimate of 5.04 ( $\mathrm{SE}=1.11$; Table 5). Individual site abundance estimates for $D$. fuscus range from 0.1 to 3.1 salamanders per site (Fig. 2A). The Hydrology FCI Model also had strong empirical support for D. fuscus abundance with a $\Delta$ AIC of 0.83 and an AIC weight of 0.40 (Table 4).

The only abundance model with empirical support for Desmognathus monticola was the Habitat FCI Model, which had an AIC weight of 0.9999 (Table 4). The beta estimate was 5.4 with a standard error of 0.63 (Table 5). Abundance estimates by site ranged from 0.2 to 10.4 for $D$. monticola (Fig. 2A).

Desmognathus ochrophaeus had one abundance model with empirical support, the Habitat FCI Model (AIC weight = 0.9994; Table 4). The beta estimate for the Habitat FCI score was 4.23 (SE $=0.58$ ) and showed a positive correlation to D. ochrophaeus abundances (Table 5). Individual site estimates of abundance ranged from 0.4 to 8.5 (Fig. 2A).

The Hydrology FCI Model was the only abundance model with empirical support for Eurycea spp. with an AIC weight of 0.88 (Table 4). The beta estimate was 1.23 (SE =0.42) and individual site abundance estimates were 2.7 to 6.2 Eurycea spp. per site (Table 5; Fig. 2B). 
Table 4. Model results for abundance estimates (lambda) of FCI scores including the number of parameters in each model (K), Akaike's Information Criterion (AIC) rankings, $\Delta$ AIC, and AIC weight $\left(\omega_{\mathrm{i}}\right)$ for the four stream salamander groups, southwest Virginia, 2013.

\begin{tabular}{|c|c|c|c|c|}
\hline FCI Abundance Models & $\mathrm{K}$ & AIC & $\Delta \mathrm{AIC}^{1}$ & $\omega_{\mathrm{i}}$ \\
\hline \multicolumn{5}{|l|}{ Desmognathus fuscus } \\
\hline$\lambda\left(\right.$ HabitatFCI), $\mathrm{p}(\text { SoilT*FlowAbove })^{2,3}$ & 5 & 300.68 & 0.00 & 0.6022 \\
\hline$\lambda($ HydrologyFCI), p(SoilT*FlowAbove) & 5 & 301.51 & 0.83 & 0.3976 \\
\hline$\lambda($ BiogeochemicalFCI $), p($ SoilT*FlowAbove $)$ & 5 & 316.89 & 16.21 & 0.0002 \\
\hline$\lambda($ Null $), p($ SoilT*FlowAbove $)$ & 4 & 332.52 & 31.84 & 0.0000 \\
\hline \multicolumn{5}{|l|}{ Desmognathus monticola } \\
\hline$\lambda($ HabitatFCI $), p(\text { SoilT*FlowBelow })^{4}$ & 5 & 644.06 & 0.00 & 0.9999 \\
\hline$\lambda($ BiogeochemicalFCI $), p($ SoilT*FlowBelow $)$ & 5 & 663.39 & 19.33 & 0.0001 \\
\hline$\lambda$ (HydrologyFCI), p(SoilT*FlowBelow) & 5 & 718.45 & 74.39 & 0.0000 \\
\hline$\lambda($ Null), $\mathrm{p}($ SoilT*FlowBelow) & 4 & 767.56 & 123.50 & 0.0000 \\
\hline \multicolumn{5}{|l|}{ Desmognathus ochrophaeus } \\
\hline$\lambda($ HabitatFCI $), p(\text { AirT } * \text { Rain })^{5}$ & 5 & 600.84 & 0.00 & 0.9994 \\
\hline$\lambda($ BiogeochemicalFCI $), p($ AirT $*$ Rain $)$ & 5 & 615.60 & 14.76 & 0.0006 \\
\hline$\lambda($ HydrologyFCI), p(AirT*Rain) & 5 & 664.87 & 64.03 & 0.0000 \\
\hline$\lambda($ Null), $\mathrm{p}($ AirT $*$ Rain $)$ & 4 & 675.88 & 75.04 & 0.0000 \\
\hline \multicolumn{5}{|l|}{ Eurycea spp. } \\
\hline$\lambda$ (HydrologyFCI), p(SoilT*Rain) & 5 & 822.64 & 0.00 & 0.8798 \\
\hline$\lambda($ BiogeochemicalFCI), $\mathrm{p}($ SoilT*Rain $)$ & 5 & 827.36 & 4.72 & 0.0831 \\
\hline$\lambda($ Null $), p($ SoilT*Rain $)$ & 4 & 829.60 & 6.96 & 0.0271 \\
\hline$\lambda($ HabitatFCI $), p($ SoilT $*$ Rain $)$ & 5 & 831.59 & 8.95 & 0.0100 \\
\hline \multicolumn{5}{|c|}{$\begin{array}{l}\text { Models with a } \triangle \mathrm{AIC}<2 \text { are considered to have a substantial level of empirical support while models with a } \Delta \mathrm{AIC} \\
\text { of } 2-4 \text { are considered to have a moderate level of empirical support. }{ }^{2} \text { SoilT is soil temperature }{ }^{3} \text { FlowAbove is } \\
\text { binomial for flow above base flow }{ }^{4} \text { FlowBelow is a binomial for flow below base flow }{ }^{5} \text { AirT is air temperature }\end{array}$} \\
\hline \multicolumn{5}{|c|}{$\begin{array}{l}\text { Table 5. Beta estimates and standard errors for each covariate in the top abundance models } \\
(\Delta \mathrm{AIC}<4) \text { for the four salamander groups, southwest Virginia, } 2013 \text {. }\end{array}$} \\
\hline Top Abundance FCI Models & & Beta & Standar & Error \\
\hline \multicolumn{5}{|l|}{ Desmognathus fuscus } \\
\hline$\lambda$. HabitatFCI & \multirow{2}{*}{\multicolumn{2}{|c|}{$\begin{array}{l}5.0402 \\
5.5785\end{array}$}} & \multicolumn{2}{|c|}{1.1057} \\
\hline$\lambda$. HydrologyFCI & & & \multicolumn{2}{|c|}{1.1638} \\
\hline \multicolumn{5}{|l|}{ Desmognathus monticola } \\
\hline$\lambda$. HabitatFCI & & .3807 & \multicolumn{2}{|c|}{0.6274} \\
\hline \multicolumn{5}{|l|}{ Desmognathus ochrophaeus } \\
\hline$\lambda$. HabitatFCI & & .2315 & \multicolumn{2}{|c|}{0.5802} \\
\hline \multicolumn{5}{|l|}{ Eurycea spp. } \\
\hline$\lambda$. HydrologyFCI & & .2330 & \multicolumn{2}{|c|}{0.4193} \\
\hline
\end{tabular}


JASMR, 2016 Volume 5 Issue 1
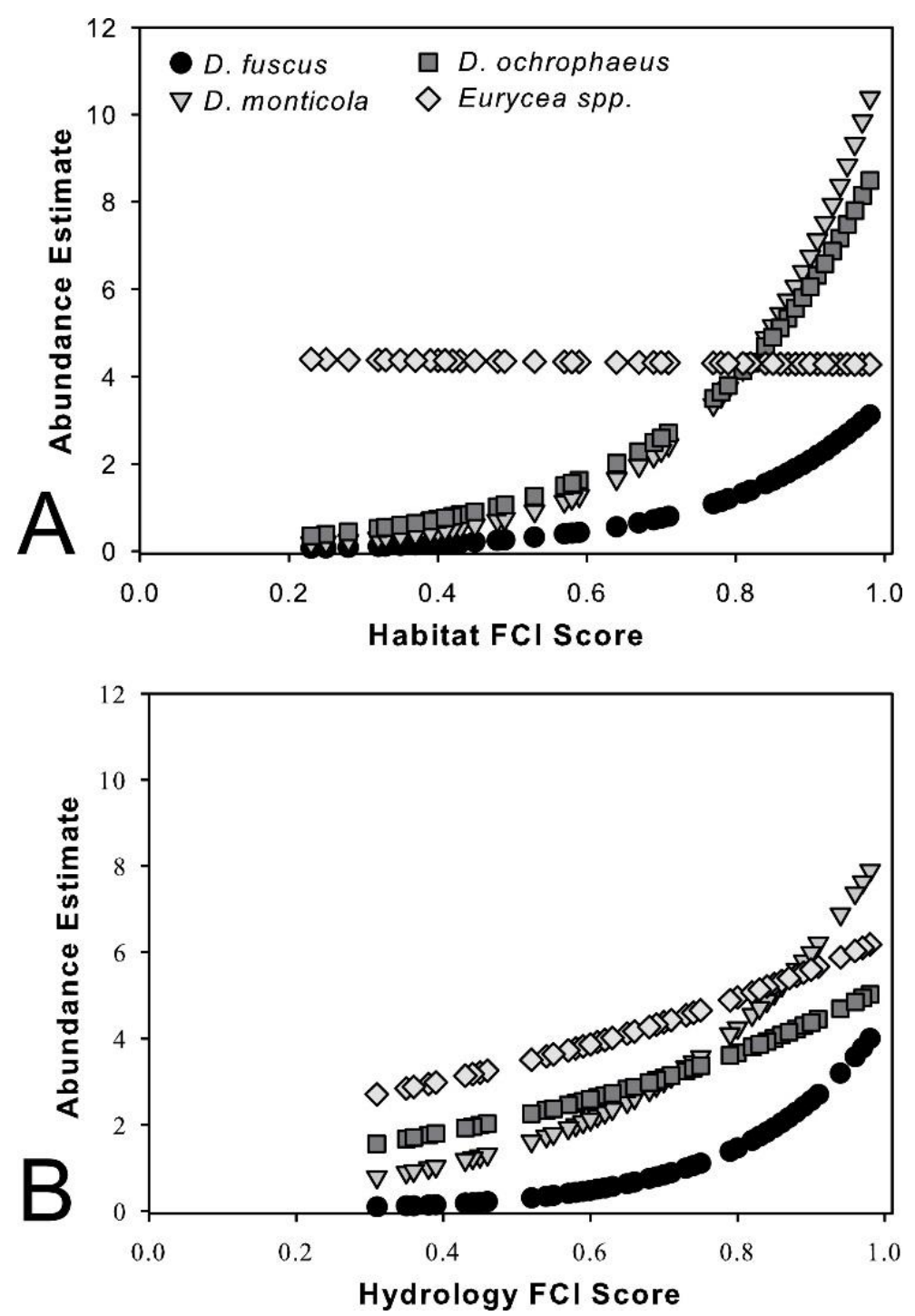

Figure 2. Individual site estimations of abundance $(\lambda)$ per $25 \mathrm{~m} \times 5 \mathrm{~m}$ quadrat and the Habitat Functional Capacity Index (FCI; see Noble et al. 2010) scores (A) and the Hydrology FCI scores (B) for Desmognathus fuscus (circles), Desmognathus monticola (triangles), Desmognathus ochrophaeus (squares), and Eurycea spp. (diamonds), southwest Virginia, summer 2013.

\section{Discussion}

The three Desmognathus species were most correlated with the Habitat FCI Model, with this model performing best for D. fuscus and D. ochrophaeus in the occupancy analysis. In the abundance analysis, the Habitat FCI Model was the best model for all three Desmognathus species. The relationship between Desmognathus spp. and the Habitat FCI score may be a function of direct correlation to the variables in the Habitat FCI. Many of the Habitat FCI variables measure riparian 
conditions such as canopy cover, riparian vegetation species richness, detritus cover, herbaceous cover, and LWD counts. Past research has indicated strong associations between canopy cover and Desmognathus abundance (Crawford and Semlitsch, 2008; Ward et al., 2008; Sweeten, 2015). Desmognathus salamanders are lungless and therefore are required to constantly have moist skin in order for oxygen exchange across the skin membrane (Petranka, 1998). Lungless salamanders have a high risk of desiccation particularly when foraging away from the stream. Canopy cover not only provides cover from solar exposure maintaining soil, stream, and air temperatures suitable for salamanders, it also increases other microhabitat characteristics associated with maintaining a cool, moist surface environment such as detritus cover. Crawford and Semlitsch (2008) reported a positive correlation between detritus depth and D. monticola and E. $b$. cirrigera abundance. In the southern Appalachians of North Carolina, Harper and Guynn (1999) found more salamanders including D. ochrophaeus and D. aeneus in moist microhabitats with increased detritus depths.

Habitat FCI scores closer to 1.0 indicate mature, less-disturbed conditions. Desmognathus spp. have been shown to be positively correlated with characteristics that often occur in more mature forests such as high canopy cover, native tree species dominance, high detritus cover, more LWD, and increased sapling/shrub densities. In the Allegheny Mountains of West Virginia, Moseley et al. (2008) reported a positive relationship between Desmognathus spp. abundance and time since forest harvest. Ford et al. (2002) demonstrated that Desmognathus spp. abundance was most correlated with stand basal area in the southern Appalachians of northern Georgia. Additionally, in a review of North American literature on amphibian ecology and forest management deMaynadier and Hunter (1995) suggested that increased numbers of salamanders in older forests were an indirect measure of microhabitat conditions such as LWD, detritus cover, and canopy.

Lower Habitat FCI scores indicate riparian habitat that is disturbed with increased herbaceous cover and areas dominated by invasive species. Walz (2002) found decreased abundances of $D$. fuscus and D. ochrophaeus in agricultural fields and pastures. Wood and Williams (2013) reported lower abundances of Desmognathus in reclaimed grassland and shrubland where there was less detritus, lower stem densities, less LWD, less canopy cover, and an increase in invasive herbaceous species such as Lespedeza as compared to forested or partially forested sites. Invasive herbaceous species may just indicate recent disturbance and grassland conditions, or it may be that invasive plant species do not produce the necessary forest-like microhabitat (i.e., leaf litter, cover, and LWD) to provide the cool, moist habitat needed for salamanders (Lemke et al., 2012). 
Unlike the results for Desmognathus spp., none of the three FCI models corresponded well with Eurycea spp. in either the occupancy or abundance analysis. The occupancy analysis of Eurycea spp. indicated empirical support for all three FCI models. However, the beta values for the FCI scores were low with large standard errors. The differences we found between Desmognathus and Eurycea may be explained by the hypothesis that stream salamanders can be grouped as either disturbance avoiders or disturbance tolerant (Surasinghe and Baldwin, 2015). Disturbance avoiders are generally long-lived salamanders that depend on forests and are sensitive to riparian disturbances. Disturbance tolerant species often can be characterized as short-lived, microhabitat generalists that can withstand riparian land uses (Surasinghe and Baldwin, 2015). Based on results from this study, Desmognathus spp. appeared to be disturbance avoiders whereas Eurycea spp. were disturbance tolerant. Several studies throughout Appalachia proper have reported that in undisturbed areas Desmognathus spp. were the dominant stream salamanders, whereas in disturbed areas Eurycea spp. were the dominant stream salamanders (Resetarits, 1997; Hyde and Simons, 2001; Hamilton, 2002). Ward et al. (2008) also reported similar findings in central Appalachia. Abundances of the disturbance tolerant E. b. cirrigera, were higher at roadside sites as compared to forested control sites while the inverse was true for Desmognathus spp. (Ward et al., 2008). Riparian disturbances, such as roads, may cause stream salamander communities to shift to disturbance tolerant species without changes in overall abundance (Ward et al., 2008). This indicates the need for studies to separate stream salamanders to species rather than examining the total, grouped salamander abundance. Eurycea are opportunistic generalists with diets largely consisting of pollutant tolerant benthic macroinvertebrates such as Chironomids (Burton, 1976; Petranka, 1984; Muenz et al., 2008; Barrett et al., 2012). We posit that one reason Eurycea is disturbance tolerant is that this genus is better able to tolerate poor water quality and riparian habitat conditions, as even in degraded conditions prey items are often readily available. However, disturbance tolerant species may not be adapted to nor depend on disturbances, and as a result these species may not be immune to localized extirpations if certain environmental thresholds are exceeded.

The implications of our study show that the Habitat FCI score is a good measure of physical instream and riparian conditions and is reflected in both Desmognathus spp. occupancy and abundance. Our results indicate that the Habitat FCI score is a good indicator of Desmognathus spp. presence and abundance. These results support the use of a presence-absence sampling design 
of Desmognathus to indicate physical stream and riparian conditions. For example, if D. fuscus, D. monticola, and D. ochrophaeus are all found at a site then it can be presumed that the Habitat FCI score is high. Our findings also show that Eurycea spp. should not be used as an indicator taxa for stream and riparian habitat conditions. As disturbance tolerators Eurycea spp. lack strong correlations in occupancy and abundance to riparian conditions.

\section{Acknowledgments}

This study was sponsored by the Appalachian Research Initiative for Environmental Science (ARIES). ARIES is an industrial affiliates program at Virginia Tech, supported by members that include companies in the energy sector. The research under ARIES is conducted by independent researchers in accordance with the policies on scientific integrity of their institutions. The views, opinions and recommendations expressed herein are solely those of the authors and do not imply any endorsement by ARIES employees, other ARIES-affiliated researchers or industrial members. Information about ARIES can be found at http://www.energy.vt.edu/ARIES.

Additional funding and in-kind support was provided by the U.S. Geological Survey, Virginia Cooperative Fish and Wildlife Research Unit, Virginia Department of Game and Inland Fisheries and the Virginia Tech Powell River Project. Access to study sites was graciously provided by Alpha Natural Resources, A \& G Coal Corporation, Red River Coal, the Heartwood Forestland Group, the USDA Forest Service, and numerous non-industrial private landowners. All salamander collection was done under a scientific collection permit issued by the Virginia Department of Game and Inland Fisheries (\#047897), and followed Virginia Tech IACUC approved protocols (\#13053FIW). Any use of trade, firm, or product names is for descriptive purposes only and does not imply endorsement by the U.S. Government. 


\section{$\underline{\text { Literature Cited }}$}

Bailey, L.L., T.R. Simons, and K.H. Pollock. 2004. Estimating site occupancy and species detection probability parameters for terrestrial salamanders. Ecological Applications. 14:692702. http://dx.doi.org/10.1890/03-5012.

Bailey, L.L., J.E. Hines, J.D. Nichols, and D.I. MacKenzie. 2007. Sampling design trade-offs in occupancy studies with imperfect detection: Examples and software. Ecological Applications. 17:281-290.

\section{http://dx.doi.org/10.1890/1051-0761(2007)017[0281:SDTIOS]2.0.CO;2.}

Barbour, M.T., J. Gerritsen, B.D. Snyder, and J.B. Stribling. 1999. Rapid Bioassessment Protocols for use in Streams and Wadeable Rivers: Periphyton, Benthic Macroinvertebrates and Fish, Second Edition. EPA 841-B-99-002. U.S. Environmental Protection Agency; Office of Water; Washington, D.C. 339 pages.

Barrett, K., S.T. Samoray, B.S. Helms, and C. Guyer. 2012. Southern two-lined salamander diets in urban and forested streams in western Georgia. Southeastern Naturalist. 11:287-296. http://dx.doi.org/10.1656/058.011.0210.

Burnham, K.P. and D.R. Anderson. 2002. Model Selection and Multimodel Inference: A Practical Information-Theoretic Approach. Springer-Verlag, New York, NY. 515 pages.

Burton, T.M. 1976. An analysis of the feeding ecology of the salamanders of the Hubbard Brook Experimental Forest, New Hampshire. Journal of Herpetology. 10:187-204. http://dx.doi.org/10.2307/1562980.

Burton, J. and J. Gerritsen. 2003. A stream condition index for Virginia non-coastal streams. Tetra Tech, Inc. Virginia Department of Environmental Quality, Richmond, Virginia. 168 p.

Crawford, J.A. and R.D. Semlitsch. 2008. Abiotic factors influencing abundance and microhabitat use of stream salamanders in southern Appalachian forests. Forest Ecology and Management. 255:1841-1847. http://dx.doi.org/10.1016/j.foreco.2007.12.005.

Davic, R.D. 1983. An investigation of salamander guild predation in a North Carolina stream: an experimental approach. PhD Dissertation, Kent State University. 237 pages. 
deMaynadier, P.G. and M.L. Hunter, Jr. 1995. The relationship between forest management and amphibian ecology: A review of North American literature. Environmental Review. 3:230261. http://dx.doi.org/10.1139/a95-012.

Dorazio, R.M., J.A. Royle, B. Soderstrom, and A. Glimskar. 2006. Estimating species richness and accumulation by modeling species occurrence and detectability. Ecology. 87:842-854. http://dx.doi.org/10.1890/0012-9658(2006)87[842:ESRAAB]2.0.CO;2.

Ford, W.M., B.R. Chapman, M.A. Menzel, and R.H. Odom. 2002. Stand age and habitat influences on salamanders in Appalachian cove hardwood forests. Forest Ecology and Management. 155:131-141. http://dx.doi.org/10.1016/S0378-1127(01)00553-9.

Gore, J.A. 1983. The distribution of Desmognathine larvae (Amphibia: Plethodontidae) in coal surface mine impacted streams of the Cumberland Plateau, USA. Journal of Freshwater Ecology. 2:13-23. http://dx.doi.org/10.1080/02705060.1983.9664572.

Hairston, N.G., Sr. 1986. Species packing in Desmognathus salamanders: experimental demonstration of predation and competition. The American Naturalist. 127:266-291. http://dx.doi.org/10.1086/284485.

Hamilton, M.S. 2002. Effects of developmental activities on streamside salamander communities in Boone County, West Virginia. Master Thesis. Marshall University, Huntington, WV. 87 pages.

Harper, C.A. and D.C. Guynn. 1999. Factors affecting salamander density and distribution within four forest types in the southern Appalachian Mountains. Forest Ecology and Management. 114:245-252. http://dx.doi.org/10.1016/S0378-1127(98)00355-7.

Hyde, E.J. and T.R. Simons. 2001. Sampling Plethodontid salamanders: Sources of variability. The Journal of Wildlife Management. 65:624-632. http://dx.doi.org/10.2307/3803013.

Hynes, H.B.N. 1968. Further studies on the invertebrate fauna of a Welsh mountain stream. Archives Hydrobiologia. 65:360-379.

Jung, R.E., S. Droege, J.R. Sauer, and R.B. Landy. 2000. Evaluation of terrestrial and streamside salamander monitoring techniques at Shenandoah National Park. Environmental Monitoring and Assessment. 63:65-79. http://dx.doi.org/10.1023/A:1006413603057. 
Kroll, A.J., J.G. MacCracken, T.C. McBride, J. Light, P. Peterson, and J. Bach. 2010. Basin-scale surveys of stream-associated amphibians in intensively managed forests. The Journal of Wildlife Management. 74:1580-1585. http://dx.doi.org/10.2193/2009-265.

Lemke, D, C.J. Schweitzer, I.A. Tazisong, Y. Wang, and J.A. Brown. 2012. Invasion of a mined landscape: What habitat characteristics are influencing the occurrence of invasive plants? International Journal of Mining, Reclamation, and Environment. 2012:1-19.

MacKenzie, D.I. and A. Royle. 2005. Designing occupancy studies: general advice and allocated survey effort. Journal of Applied Ecology. 42:1105-1114. http://dx.doi.org/10.1111/j.13652664.2005.01098.x.

MacKenzie, D.I. and A. Royle. 2005. Designing occupancy studies: general advice and allocated survey effort. Journal of Applied Ecology. 42:1105-1114. http://dx.doi.org/10.1111/j.13652664.2005.01098.x.

McNab, W.H. and P.E. Avers. 1995. Ecological subregions of the United States. Chapter 20. U.S. Forest Service Technical Report WO-WSA-5.

Maddock, I. 1999. The importance of physical habitat assessment for evaluating river health. Freshwater Biology. 41:373-391. http://dx.doi.org/10.1046/j.1365-2427.1999.00437.x.

Maxwell, A.E., M.P. Strager, T.A. Warner, N.P. Zegre, and C.B. Yuill. 2014. Comparison of NAIP orthophotography and RapidEye satellite imagery for mapping of mining and mine reclamation. GIScience and Remote Sensing. http://dx.doi.org/10.1080/15481603.2014.912874.

Morse, J.C., B.P. Stark, and W.P. McCafferty. 1993. Southern Appalachian streams at risk: implications for mayflies, stoneflies, caddisflies, and other aquatic biota. Aquatic Conservation. 3:293-303. http://dx.doi.org/10.1002/aqc.3270030404.

Moseley, K.R., W.M. Ford, J.W. Edwards, and T.M. Schuler. 2008. Long-term partial cutting impacts on Desmognathus salamander abundance in West Virginia headwater streams. Forest Ecology and Management. 254:300-307. http://dx.doi.org/10.1016/j.foreco.2007.03.073.

Muenz, T.K., S.W. Golladay, L.L. Smith, and G. Vellidis. 2008. Diet and abundance of southern two-lined salamander larvae (Eurycea cirrigera) in streams within an agricultural landscape, 
southwest Georgia. Southeastern Naturalist. 7:691-704. http://dx.doi.org/10.1656/1528-70927.4.691.

Noble, C.V., J.F. Berkowitz, and J. Spence. 2010. Operational draft regional guidebook for the functional assessment of high-gradient ephemeral and intermittent headwater streams in western West Virginia and eastern Kentucky. ERDC/EL TR-10-11. US Army of Corps of Engineers, Vicksburg, MS. 117 pages.

Noble, C.V., E.A. Summers, and J.F. Berkowitz. 2014. Validating the operational draft regional guidebook for the functional assessment of high-gradient ephemeral and intermittent headwater streams in western West Virginia and eastern Kentucky. ERDC/EL TR-14-7. US Army of Corps of Engineers, Vicksburg, MS. 228 pages.

Omernik, J.M. 1987. Ecoregions of the continuous United States. Annuals of the Association of American Geographers. 77:118-125. http://dx.doi.org/10.1111/j.1467-8306.1987.tb00149.x.

Petranka, J.W. 1984. Ontogeny of the diet and feeding behavior of Eurycea bislineata larvae. Journal of Herpetology. 18:48-55. http://dx.doi.org/10.2307/1563671.

Petranka, J.W. 1998. Salamanders of the United States and Canada. Smithsonian Institute Press, Washington DC, 587 pages.

Resetarits, W.J., Jr. 1997. Differences in an ensemble of streamside salamanders (Plethodontidae) above and below a barrier to brook trout. Amphibia-Reptilia. 18:15-25. http://dx.doi.org/10.1163/156853897X00279.

Royle, J.A. 2004. N-mixture models for estimating population size from spatially replicated counts. Biometrics. 60:108-115. http://dx.doi.org/10.1111/j.0006-341X.2004.00142.x.

Simmons, J.A., W.S. Currie, K.N. Eshleman, K. Kuers, S. Monteleone, T.L. Negley, B.R. Pohladand, and C.L. Thomas. 2008. Forest to reclaimed mine land use change leads to alteredecosystem structure and function. Ecological Applications. 18:104-118. http://dx.doi.org/10.1890/07-1117.1.

Stout, B. and J.B. Wallace. 2005. A survey of eight major aquatic insect orders associated with small headwater streams subject to valley fills from mountaintop mining. Mountaintop mining/valley fills in Appalachia: Final Programmatic Environmental Impact Statement. U.S. Environmental Protection Agency, Washington, D.C. 13 pages. 
Surasinghe, T.D. and R.F. Baldwin. 2015. Importance of riparian forest buffers in conservation of stream biodiversity: Responses to land uses by stream-associated salamanders across two southeastern temperate ecoregions. Journal of Herpetology. 49:12p https://doi.org/10.1670/14$\underline{003 .}$

Sweeten, S.E. 2015. The effects of microhabitat and land use on stream salamander occupancy and abundance in the southwest Virginia Coalfields. PhD Dissertation. Virginia Polytechnic Institute and State University, Blacksburg, VA.

Virginia Department of Game and Inland Fisheries (VDGIF). 2005. Virginia's comprehensive wildlife conservation strategy. Virginia Department of Game and Inland Fisheries, Richmond, Virginia.

Walz, A. 2002. The study of associations between Maryland's amphibian species and habitat parameters at local and landscape scales. PhD Dissertation. University of Maryland, College Park, MD. 222 pages.

Ward, R.L., J.T. Anderson, and J.T. Petty. 2008. Effects of road crossings on stream and streamside salamanders. The Journal of Wildlife Management. 72:760-771. http://dx.doi.org/10.2193/2006-420.

Welsh, H.H. and L.M. Ollivier. 1998. Stream amphibians as indicators of ecosystem stress: A case study from California's redwoods. Ecological Applications. 8:1118-1132. http://dx.doi.org/10.2307/2640966.

Welsh, H.H., G.R. Hodgson, and A.J. Lind. 2005. Ecogeography of herpetofauna of a northern California watershed: Linking species patterns to landscape processes. Ecography. 28:521536. http://dx.doi.org/10.1111/j.0906-7590.2005.04024.x.

Wood, P.B. and J.M. Williams. 2013b. Terrestrial salamander abundance on reclaimed mountaintop removal mines. Wildlife Society Bulletin. 37:815-823. http://dx.doi.org/10.1002/wsb.319.

Woodward, S.L. and R.L. Hoffman. 1991. The nature of Virginia. Pages 23-48 In K. Terwillinger, Editor. Virginia's Endangered Species. McDonald and Woodward Publishing, Blacksburg, Virginia. 